\title{
Research on Incentive Mechanism of FPLs / TPLs Company in Agricultural Product Financing under Reciprocal Preference
}

\author{
Xu Peng ${ }^{1, *}$ \\ ${ }^{1}$ College of Management, Southwest University of Political Science and Law, Chongqing 401120, China \\ *Correspondence: College of Management, Southwest University of Political Science and Law, Chongqing 401120, \\ China. E-mail: xupeng8122@126.com
}

Received: November 4, 2015 Accepted: January 5, $2016 \quad$ Online Published: March 30, 2016

doi:10.5430/mos.v3n2p1

URL: http://dx.doi.org/10.5430/mos.v3n2p1

\begin{abstract}
This paper investigates the contract between a FPL(fourth party logistics) and a TPL(third party logistics) in agricultural product financing. FPLs will subcontract logistics tasks to TPLs after they accept tasks from banks. TPLs' effort has a positive impact on FPLs' profits, as well as the relationship between FPLs and banks. Thus it is important to course TPLs to devote more effort in that work. Using principal-agency theory, we establish a multi-task principal-agent model, and consider the situation with TPLs' reciprocal preference. Results show that TPLs with reciprocal preference will invest extra effort when TPLs provide a higher reward. The stronger the sense of the TPLs' reciprocal preference is, the more the TPLs will increase extra effort, and different TPLs have different reaction when FPLs provide the same reward. Thus, FPLs can gain more profits through designing appropriate incentive contract.
\end{abstract}

Keywords: agricultural product financing; third-party logistics (TPLs); fourth-party logistics(FPLs); incentive contract

\section{Introduction}

Since its introduction, inventory financing has attracted wide attention. Inventory financing theory is gradually improving, however, there is little research focusing on agricultural product financing (Li, 2011). Agricultural product financing provides an effective financing path for rural cooperatives, agricultural enterprises, and farmers in agricultural product supply chain. Agricultural product financing is that ASMEs (agricultural small-medium sized enterprises) place agricultural products into warehouses designated by banks as collateral for loans. The security of banks' credit mainly depends on the collateral and the ASME's actual performance. There are three main parties involved in the transaction: financial institutions, logistics enterprises and customers (Luo, Zhu \& Chen, 2002). In practice, logistics enterprises play a crucial role, similar to a bridge between banks and ASMEs. On the one hand, they provide services, e.g., value assessment, management, price fluctuation detection, information sharing, storage, transportation etc. On the other hand, they provide professional logistics services to ASMEs. In other word, it is necessary for logistics enterprises to participate in the process to ensure effective development of agricultural product financing. There are two primary reasons for that: (1) Banks don't have appropriate storage facilities to deposit guaranteed inventories; (2) Banks is lack of ability and skill to transfer or deliver inventories, and are not good at value evaluation, price detection, inventories disposal etc. In recent years, many logistics enterprises participate in agricultural product financing ( $\mathrm{Li}$, Feng \& Xu, 2007). United Parcel Service of America (UPS) buys the first bank in the United Stated, and set up a special financial company, to provide customers with a full range of logistics and supply chain financial services. Guangdong Nanchu Warehousing Management Co. Ltd began to develop the business through cooperating with several banks such as Shenzhen Development Bank, Guangdong Development Bank, Shanghai Pudong Development Bank, Bank of Communications. In 2014, the value of loans from banks through inventory financing totaled about 20 billion RMB. In 2010, China Sinotrans \& CSC Holdings Co. Ltd and Worldwide Express Mail Service Co. Ltd cooperate with several banks to develop the business. These examples show that logistics enterprises are necessary to participate in the business.

Although there are no models in the literature addressing an incentive contract in agricultural product financing, 
there is a substantial literature on incentive mechanism in inventory financing. Li, Xu \& Feng (2007) applied game theory to explore incentive mechanisms between banks and logistics enterprises under completed information. The results show that compared with promoting customers, banks can reduce more risks through inspiring logistics companies. Xu \& Wang (2010) studied the design of incentive and supervisor mechanisms between banks and TPLs. Result shows that when loan enterprises help banks incentivize and supervise TPLs together, banks will reduce costs. Wei, Sun \& Shuai (2010) analyzed incentive contracts between banks and TPLs. Wang \& Xu (2010) researched the incentive contracts between banks and TPLs under TPLs' irrational behaviors. They found that when banks offer TPLs more reward, TPLs devote more efforts to the work. He, Wang \& Jiang (2012) used the game theory method, and also studied the question that banks prevent TPLs and loan enterprises from collusion to loan. Zhang \& Wang (2014) extended the catastrophe progression model and applied it to diagnose the project risk in inventory financing. He, Wang \& Jiang (2013) presented an application of Copula-GARCH model in the dynamic estimation of the inventory portfolios' VaR with rolling time window based on the principle of risk diversification of Markowitz's.

In current literature on incentive mechanism in inventory financing, logistics enterprises are defined as TPLs. In agricultural product financing, agricultural products are perishable, not easy to transport and store. This requires a higher logistics service and optimization scheme. So only TPLs joining in the activity are not enough, because they only provide basic logistics service such as transportation, storage, supervision etc., and unable to provide integrated logistics services (Bade \& Mueller, 1999). Therefore, this paper considered the case with FPLs involved in the transactions, and focused on agricultural product financing. FPLs work as an integrator of supply chain and provide a complete supply chain solution through integration of their own technology, information and other resources. FPLs focus on the integration and optimization of the entire logistics system resources, which is different from TPLs' basic operations, such as shipping, storage, etc. (Hertz \& Alfredsson, 2003; Fulconis, Saglietto \& Pache, 2006 ). FPLs are responsible for the design and optimization of logistics schemes, subcontracting to TPLs (Stefansson, 2006). It is the only connection between TPLs and customers, management and supervision of TPLs, and share risks and benefits with customers (Visser, 2007). FPLs' participation overcomes the bottleneck of agricultural products financing, and contributes to smooth development of the transactions. The bank is more willing to cooperate with FPLs in order to guarantee loan security. However, FPLs don't complete logistics tasks entrusted by banks on their own; they usually subcontract tasks to TPLs. Naturally, whether TPLs finish the tasks with high quality not only has an impact on the successful development of agricultural product financing, but also on the long-term stable relationship between FPLs and banks. Therefore, it is significant for FPLs to design the contract in order to make TPLs invest more effort in the work. In order to be more consistent with practical situation, we consider TPLs' reciprocal preference when constructing the model.

This paper is organized as follows. In Section 2, we explain the "reciprocal preference" and define the model of agricultural product financing in an environment with uncertainty and moral hazards on the basis of some assumptions. In Section 3, we construct the model considering TPLs' reciprocal preference and analyze the question from two aspects. In Section 4, we give numerical analysis. Finally, section 5 concludes the paper and gives suggestions: FPLs should design an incentive mechanism according to TPLs' irrational behaviors.

\section{Reciprocal Preference and Model Hypothesis}

\subsection{Reciprocal Preference}

Most current economic models assume that people purse only their own material self-interest and do not care about "social goals". One exception to self-interest which has received some attention by economists is simple altruism: people may care not only about their own well-being, but also about the well-being of others. Yet psychological evidence indicates that most altruistic behavior is more complex: people do not seek uniformly to help other people; rather, they do so according to how generous these other people are being. Indeed, the same people who are altruistic to other altruistic people are also motivated to hurt those who hurt them. If somebody is being nice to you, fairness dictates that you be nice to him. If somebody is being mean to you, fairness allows - and vindictiveness dictates - that you be mean to him (Rabin, 1993; Ernst \& Schmidt, 1999). Therefore, reciprocal preference refers to when someone is nice to you, you will be friendly to others. For this paper, when FPLs show kindness to TPLs, TPLs will friendly give extra efforts in return.

\subsection{The Model}

Consider an ASME, that relies on a bank for $I$ units of working capital. Because of the lack of sufficient fixed assets, the ASME needs to offer agricultural products as a collateral (it obtains loans from the bank through 
agricultural product financing). The bank provides the SME with $I$ units of money, the interest rate is $r$, loan period is $t$. The interest ASMEs pay to banks defined as $\psi=I r t$. The bank entrusts logistics tasks, such as transportation, value evaluation, management, supervision, price fluctuation detection, disposal of agricultural products, disposal and exchange of information to FPLs, and then FPLs subcontract these tasks to TPLs according to their own strengths.

A few assumptions are needed for a tractable model. We first assume that TPLs are not totally rational, that is, not pursuit of personal profit's maximization, and then assume that the number of TPLs joining business is $i$ $(i=1,2 \ldots . n)$. FPLs assess the result of tasks completion using five non-profit indexes, assuming assessment result is, $X_{i i}=\left(x_{i 1}, x_{i 2}, x_{i 3}, x_{i 4}, x_{i 5}\right)$. Among them, $x_{i 1}$ denotes the value evaluation index, $x_{i 2}$ denotes the supervision index, $x_{i 3}$ denotes the transportation index, $x_{i 4}$ denotes the index of disposal of agricultural product when SMEs default, $x_{i 5}$ denotes information sharing index.

It is assumed that FPLs gives TPLs' rewards:

$$
T\left(X_{i}\right)=\sum_{j=1}^{5} \beta_{i j} X_{i j}+\left(w_{i}+\delta_{i}\right) \quad(i=1,2, \ldots n)
$$

Wherein $T\left(X_{i}\right)$ defined as the reward to the TPLs given by the FPLs, $w_{i}$ indicates that a fixed reward is paid for completion of all basic tasks, $\delta_{i}$ denotes an extra fixed reward to TPLs given by FPLs, $\beta_{i j}$ is an incentive coefficient for completing tasks, proposed by the FPLs. Among them, $x_{i j}=A\left(a_{i j}+\Delta a_{i j}\right)+\varepsilon_{i j}$, the concrete function is as follows:

$x_{i 1}=A_{i 1}\left(a_{i 1}+\Delta a_{i 1}\right)+\varepsilon_{i 1}$

$x_{i 2}=A_{i 2}\left(a_{i 2}+\Delta a_{i 2}\right)+\varepsilon_{i 2}$

$x_{i 3}=A_{i 3}\left(a_{i 3}+\Delta a_{i 3}\right)+\varepsilon_{i 3}$

$x_{i 4}=A_{4}\left(a_{i 4}+\Delta a_{i 4}\right)+\varepsilon_{i 4}$

$x_{i 5}=A_{i 5}\left(a_{i 5}+\Delta a_{i 5}\right)+\varepsilon_{i 5}$

To simplify analysis, it is assumed that the bigger the values of all indexes are, the better they are. Wherein, $\Delta a_{i i}$ denotes extra effort TPLs offer as reaction to FPLs' kindness, $a_{i i}(j=1,2,3,4)$ denotes TPLs' effort for completing the task index, $A_{i j}$ denotes abilities TPLs possess, such as operation processes, operational experience, technology, and the larger the value of $A_{i i}$, the easier TPLs complete the task. $\varepsilon_{i i}$ denotes external factors affecting completion of tasks. It is assumed that $\varepsilon_{i j} \sim\left(0, \sigma_{i j}{ }^{2}\right)$, and these factors are independent of each other.

It's assumed that FPLs benefit from service subcontract.

$$
R_{i}\left(X_{i}\right)=\sum_{j=1}^{5} \eta_{i j} x_{i j}, \quad(i=1,2, \ldots . . n)
$$

Wherein, $\eta_{i j}$ is contribution coefficient, profits that FPLs gain from all service subcontract are as follows:

$$
\lambda=\sum_{i=1}^{n}\left(R_{i}-T_{i}\right)-\phi
$$

It is assumed that FPLs are risk neutral and act to maximize their expected profits; therefore, certainty equivalent income equals expected value of total earnings, that is: 


$$
H=E(\lambda)=\sum_{i=1}^{n}\left(\sum_{j=1}^{5}\left(\eta_{i j}-\beta_{i j}\right) x_{i j}+\sum_{j=1}^{5} \beta_{i j} x_{i j 0}-\left(w_{i}+\delta_{i}\right)\right)-I r t, \quad(i=1,2, \ldots n)
$$

We also assume the function of the TPLs' effort cost is $C_{i}$, and $C_{i}=\frac{1}{2} b_{i} \sum_{j=1}^{5}\left(a_{i j}+\Delta a_{i j}\right)^{2},(i=1,2, \ldots n)$, and $C_{i}^{\prime}\left(a_{i j}\right)>0, C_{i}^{\prime \prime}\left(a_{i j}\right)>0$.

Wherein, $b_{i}$ is cost coefficient, related to its ability $A_{i j}$, the better the abilities or skills are, the smaller the value of $b_{i}$.

With above assumption and analysis, the TPLs' actual income:

$$
M_{i}=T_{i}-C_{i}=\sum_{j=1}^{5} \beta_{i j} x_{i j}+w_{i}+\delta_{i}-\frac{1}{2} b_{i} \sum_{j=1}^{5} a_{i j}{ }^{2} \quad(i=1,2, \ldots n)
$$

It is assumed that TPLs' risk type for risk aversion, the value of risk aversion is $\rho_{i}$, certainty of profits $V_{i}$ is as follows:

$$
V_{i}=E\left(M_{i}\right)-\frac{1}{2} \rho_{i} \operatorname{var}\left(M_{i}\right)=\sum_{j=1}^{5} \beta_{i j} x_{i j}+\left(w_{i}+\delta_{i}\right)-\frac{1}{2} b_{i} \sum_{j=1}^{5}\left(a_{i j}+\Delta a_{i j}\right)^{2}-\frac{1}{2} \rho_{i} \sum_{j=1}^{5} \beta_{i j}^{2} \sigma_{i j}^{2},(i=1,2, \ldots n) .
$$

\section{Contract between FPLs and TPLs with Reciprocal Preference}

\subsection{Incentive Mechanism with $\tau$ Being Constant}

Refer to the relevant sections, FPLs' profit maximization problem is:

$$
\begin{gathered}
\operatorname{Max}_{\beta_{i j}, w} H=E(\lambda) \\
\text { s.t.IC }: V_{i} \geq v_{i}+\tau_{i} \quad(i=1,2, \ldots n) \\
I R: a_{i j} \in \arg \max V_{i}=E\left(M_{i}\right)-\frac{1}{2} \rho_{i} \operatorname{var}\left(M_{i}\right) \quad(i=1,2, \ldots n), \quad(j=1,2, \ldots 5)
\end{gathered}
$$

Wherein, $\tau$ denotes retained earnings the TPLs increase.

This problem (4) is found to have a unique solution, which is the following:

$$
\sum_{j=1}^{5} \Delta a_{i j}^{2}=\frac{2\left(\delta_{i}-\tau_{i}\right)}{b_{i}}
$$

Here we use $\Delta a_{i}^{2}$ to substitutes for $\sum_{j=1}^{5} \Delta a_{i j}{ }^{2}$, and then 


$$
\Delta a_{i}^{2}=\frac{2\left(\delta_{i}-\tau_{i}\right)}{b_{i}}
$$

That is,

$$
\Delta a_{i}=\sqrt{\frac{2\left(\delta_{i}-\tau_{i}\right)}{b_{i}}}
$$

Proposition 1 The TPLs will increase extra effort if $\delta_{i} \geq \tau_{i}, \Delta a_{i} \geq 0$.

According to above analysis, the TPLs are not totally rational, so $\delta_{i} \geq \tau_{i}$ is possible and reasonable, that is, the TPLs will pay more efforts in return when the FPLs' offer more fixed rewards.

With the existence of the TPLs' behavior of reciprocal preference, the FPLs' profits are:

$$
H^{\prime}=E\left(\lambda^{\prime}\right)=\sum_{i=1}^{n}\left(\left(\eta_{i}-\beta_{i}\right)\left(\frac{A_{i} \beta_{i}}{b_{i}}+\sqrt{\frac{2\left(\delta_{i}-\tau_{i}\right)}{b_{i}}}\right)+\sum_{j=1}^{5} \beta_{i j} x_{i j 0}-\left(w_{i}+\delta_{i}\right)\right)-I r t
$$

The FPLs will maximize their own profits through choosing the optimal $\delta$. By equation (5), and then:

$$
\frac{\partial H^{\prime}}{\partial \delta}=\sum_{i=1}^{n}\left(\frac{2\left(\eta_{i}-\beta_{i}\right) \sqrt{b_{i}}}{\sqrt{2\left(\delta_{i}-\tau_{i}\right)}}-1\right)
$$

By $\frac{\partial H^{\prime}}{\partial \delta}=0$, we get the optimal $\delta$ :

$$
\delta_{i}=\tau_{i}+2 b_{i} \sum_{j=1}^{5}\left(\eta_{i j}-\beta_{i j}\right)^{2}=\tau_{i}+2 b_{i} \sum_{j=1}^{5} \eta_{i j}{ }^{2}\left(1-\frac{A_{i j}{ }^{2}}{A_{i j}{ }^{2}+b_{i} \rho_{i} \sigma_{i j}{ }^{2}}\right)^{2}
$$

Because $\eta_{i j} \geq 0,1-\frac{A_{i j}{ }^{2}}{A_{i j}{ }^{2}+b_{i} \rho_{i} \sigma_{i j}{ }^{2}} \geq 0, \eta_{i j}{ }^{2}\left(1-\frac{A_{i j}{ }^{2}}{A_{i j}{ }^{2}+b_{i} \rho_{i} \sigma_{i j}{ }^{2}}\right)^{2} \geq 0$.

By equation (6), the relationship between $\delta$ and $\tau: \delta_{i} \geq \tau_{i}$

Put equation (5) into equation (4), we get the FPLs' profits:

$$
H^{\prime}=E\left(\lambda^{\prime}\right)=\sum_{i=1}^{n}\left(\sum_{j=1}^{5} \frac{A_{\mathrm{ij}} \beta_{i j}\left(\eta_{i j}-\beta_{i j}\right)}{b_{i}}+2\left(1-b_{i}\right) \sum_{j=1}^{5}\left(\eta_{i j}-\beta_{i j}\right)^{2}+\sum_{j=1}^{5} \beta_{i j} x_{i j 0}-w_{i}-\tau_{i}\right)-I r t
$$

Under the situation that the TPLs are rational, the FPLs' profits are following:

$$
H=E(\lambda)=\sum_{i=1}^{n}\left(\sum_{j=1}^{5} \frac{A_{i j} \beta_{i j}\left(\eta_{i j}-\beta_{i j}\right)}{b_{i}}+\sum_{j=1}^{5} \beta_{i j} x_{i j 0}-w_{i}\right)-I r t
$$

Comparing equation (7) with equation(8), and then: 


$$
H^{\prime}=H+\sum_{i=1}^{n}\left(2\left(1-b_{i}\right) \sum_{j=1}^{5}\left(\eta_{i j}-\beta_{i j}\right)^{2}-\tau_{i}\right)
$$

Proposition 2. When $2\left(1-b_{i}\right) \sum_{j=1}^{5}\left(\eta_{i j}-\beta_{i j}\right)^{2} \geq \tau_{i}, H^{\prime} \geq H$.

The stronger the TPLs' sense of reciprocal preference is, the smaller $\tau_{i}$ is, thus, the value of $\Delta a_{i}$ is bigger when $\tau_{i}$ is sufficiently small, $2\left(1-b_{i}\right) \sum_{j=1}^{5}\left(\eta_{i j}-\beta_{i j}\right)^{2} \geq \tau_{i}$.

\subsection{Incentive Mechanism with $\underset{\tau}{\tau}$ and $\delta$ Correlation}

When reciprocal preference exists, the more the FPLs offer fixed rewards $\delta$ ), the fewer increased retained earnings $(\tau)$ the TPLs require, because the TPLs will sacrifice their own material well-being in return. Therefore, there is a functional relationship between $\delta$ and $\tau$. It's assumed $\tau=y(\delta)$, and $y^{\prime}(\delta) \leq 0$, and different the TPLs have different reciprocal preference, that is, $\tau_{i} \neq \tau_{i}$, if the TPL 's sense of reciprocal preference is stronger than TPL 's, and then, $y_{i}(\delta) \leq y_{j}(\delta), y_{i}^{\prime}(\delta) \leq y_{j}^{\prime}(\delta)$. Then, the FPLs' expected profits are following:

$$
H^{\prime}=E\left(\lambda^{\prime}\right)=\sum_{i=1}^{n}\left(\left(\eta_{i}-\beta_{i}\right)\left(\frac{A_{i} \beta_{i}}{b_{i}}+\sqrt{\frac{2\left(\delta_{i}-y\left(\delta_{i}\right)\right)}{b_{i}}}\right)+\sum_{j=1}^{5} \beta_{i j} x_{i j 0}-\left(w_{i}+\delta_{i}\right)\right)-I r t
$$

By equation (9), and then:

$$
\frac{\partial H^{\prime}}{\partial \delta}=\sum_{i=1}^{n}\left(\frac{2\left(\eta_{i}-\beta_{i}\right)\left(1-y^{\prime}\left(\delta_{i}\right)\right) \sqrt{b_{i}}}{\sqrt{2\left(\delta_{i}-\tau_{i}\right)}}-1\right)
$$

By $\frac{\partial H^{\prime}}{\partial \delta}=0$, and then:

$$
\delta_{i}=y\left(\delta_{i}\right)+2 b_{i}\left(1-y^{\prime}\left(\delta_{i}\right)\right)^{2} \sum_{j=1}^{5} \eta_{i j}{ }^{2}\left(1-\frac{A_{i j}{ }^{2}}{A_{i j}{ }^{2}+b_{i} \rho_{i} \sigma_{i j}{ }^{2}}\right)^{2}
$$

The FPLs' optimal profits are:

$$
H^{\prime}=H+\sum_{i=1}^{n}\left(2\left(1-b_{i}\right)\left(1-y^{\prime}\left(\delta_{i}\right)\right)^{2} \sum_{j=1}^{5}\left(\eta_{i j}-\beta_{i j}\right)^{2}-y\left(\delta_{i}\right)\right)
$$

Proposition 3. When $\left(1-b_{i}\right)\left(1-y^{\prime}\left(\delta_{i}\right)\right)^{2} \sum_{j=1}^{5}\left(\eta_{i j}-\beta_{i j}\right)^{2}-y\left(\delta_{i}\right) \geq 0, \quad H^{\prime} \geq H$.

The stronger the TPLs' sense of reciprocal preference is, the smaller $y\left(\delta_{i}\right)$ is. When $y\left(\delta_{i}\right)$ is small enough,

$$
\left(1-b_{i}\right)\left(1-y^{\prime}\left(\delta_{i}\right)\right)^{2} \sum_{j=1}^{5}\left(\eta_{i j}-\beta_{i j}\right)^{2}-y\left(\delta_{i}\right) \geq 0
$$


Proposition 4. When FPLs provide the same extra reward, $\delta_{i}=\delta_{j}, \Delta H_{i} \geq \Delta H_{j}$ if $\tau_{i} \geq \tau_{j}$.

If $\tau_{i} \geq \tau_{j}$, and then, $\tau_{i}=y_{i}(\delta) \leq \tau_{j}=y_{j}(\delta)$, so $\Delta a_{i}=\sqrt{\frac{2\left(\delta-\tau_{i}\right)}{b}} \geq \Delta a_{j}=\sqrt{\frac{2\left(\delta-\tau_{j}\right)}{b}}$. By $y_{i}^{\prime}(\delta) \leq y_{j}^{\prime}(\delta) \leq 0$, and then, $\sum_{i=1}^{n}\left(2(1-b)\left(1-y^{\prime}(\delta)\right)^{2} \sum_{j=1}^{5}\left(\eta_{j}-\beta_{j}\right)^{2}-y(\delta)\right) \geq \sum_{i=1}^{n}\left(2(1-b)\left(1-y^{\prime}(\delta)\right)^{2} \sum_{j=1}^{5}\left(\eta_{j}-\beta_{j}\right)^{2}-y\left(\delta_{j}\right)\right)$

So $\Delta H_{i} \geq \Delta H_{j}$.

\section{Numerical Analysis}

In order to show the feasibility and the practical significance of the results, we give a set of data. To simplify calculation, it is assumed that there are only two TPLs, and two kinds of task indicators, and TPLs have the same ability for the same tasks, that is, $A_{11}=A_{12}=5, A_{21}=A_{22}=10$. Both kinds of tasks have the same income contribution, $\quad \eta_{1 j}=\eta_{2 j}=0.6$. Besides, $\rho_{1}=\rho_{2}=0.3 \quad, \quad b_{1}=b_{2}=0.2 \quad, \quad \beta_{11}=\beta_{12}=\frac{\eta_{j j} A_{j}^{2}}{A_{j}^{2}+b_{1 j} \rho \sigma_{1 j}^{2}}=0.19$, $\beta_{21}=\beta_{22}=\frac{\eta_{2 j} A_{2 j}{ }^{2}}{A_{2 j}{ }^{2}+b_{2 j} \rho_{2} \sigma_{2 j}{ }^{2}}=0.39$. The influence of external factors is the same, and is subject to the normal distribution, $\varepsilon-(0,900)$. It's assumed that the specific expression of two variables is like that: $\tau_{1}=y\left(\delta_{1}\right)=-0.02 \sigma+0.15 \quad, \quad \tau_{2}=y\left(\delta_{2}\right)=-0.01 \sigma_{1}+0.2 \quad$. So $\quad y^{\prime}\left(\delta_{1}\right)=-0.02 \quad, \quad y^{\prime}\left(\delta_{2}\right)=-0.01 \quad$. And then, $\sum_{i=1}^{n}\left(2\left(1-b_{i}\right)\left(1-y^{\prime}\left(\delta_{i}\right)\right)^{2} \sum_{j=1}^{2}\left(\eta_{i j}-\beta_{i j}\right)^{2}\right)=0.354$, put the number into the equation (9), and then, $H^{\prime}=H+0.354-\left[y\left(\delta_{1}\right)+y\left(\delta_{2}\right)\right]$. We get the number of the FPLs' increased income: $\Delta H=H^{\prime}-H=0.354-\left[y\left(\delta_{1}\right)+y\left(\delta_{2}\right)\right]$. In order to make the results have practical significance, it is necessary to satisfy the following conditions: $\delta \geq 0, \tau \geq 0$, and $\tau \leq \delta$. So the effective range of $\delta_{1}$ and $\delta_{2}$ is: $\delta_{1} \subset\left[\frac{5}{34}, 1\right]$, $\delta_{2} \subset\left[\frac{20}{101}, 1\right]$. And then, the effective range of $y\left(\delta_{1}\right)$ and $y\left(\delta_{2}\right)$ are: $y\left(\delta_{1}\right) \subset[0.13,0.15]$, $y\left(\delta_{2}\right) \subset[0.19,0.20]$. 
In order to further understand the impact of additional rewards on the TPLs' effort and the FPLs' profits, the paper selects several groups of data in effective set. The results are shown in the table 1.

Table 1. The Change of the TPLs' Efforts and the FPLs' Profits as the Change of the FPLs' Extra Rewards

\begin{tabular}{lllllllll}
\hline$\delta$ & 0.2 & 0.3 & 0.4 & 0.5 & 0.6 & 0.7 & 0.8 & 1.0 \\
$\tau_{1}$ & 0.146 & 0.144 & 0.142 & 0.140 & 0.138 & 0.136 & 0.134 & 0.130 \\
$\tau_{2}$ & 0.198 & 0.197 & 0.196 & 0.195 & 0.194 & 0.193 & 0.192 & 0.190 \\
\hline$\Delta a_{1}$ & 0.760 & 1.251 & 1.611 & 1.902 & 2.153 & 2.362 & 2.561 & 3.141 \\
$\Delta a_{2}$ & 0.045 & 1.018 & 1.415 & 1.738 & 2.015 & 2.253 & 2.466 & 2.846 \\
$\Delta H$ & 0.010 & 0.013 & 0.016 & 0.019 & 0.022 & 0.025 & 0.028 & 0.034 \\
\hline
\end{tabular}

In the effective set, both TPLs' effort will increase when the FPLs provide extra rewards. But the increased number is different, which is related to their reciprocal preference. The stronger reciprocal preference is, the more the increased effort. The FPLs' profits don't reduce when they offer extra rewards, on the contrary, the profits increase. Based on the above analysis, the FPLs should design different incentive mechanism according to the characteristics of the TPLs' reciprocal preference to achieve more profit.

\section{Conclusions}

Agricultural product financing expands an application range of inventory financing. It provides an effective way for agricultural enterprises to overcome difficulties, which is useful for the increase of farmers' incomes, the improvement of agricultural modernization and the development of rural economics. However, agricultural products are difficulty for transportation, storage, supervision etc. which determines agricultural product financing need high level of logistics service. FPLs with the optimization and resource integration ability can satisfy the need, and are able to reduce the risks. Based on above analysis, we introduce the FTLs into our models, and explore the incentive mechanism between the FPLs and the TPLs, the purpose is to make the TPLs devote more effort into work, and we consider the TPLs' reciprocal preference, which will be more consistent with practical situation. Results show that when the FPLs provide more fixed rewards, the TPLs with irrational behaviors will provide more efforts in return. This behavior leads to reduce of the TPLs' earnings, but contribute to increase the FPLs' revenue. Although we get some new findings in our study, there are still many problems need to be further explored about agricultural product financing, such as risks management, logistics service pricing, value ratio determination, members selection, prices fluctuation supervision and so on.

\section{Acknowledgement}

This paper is funded by youth project of Ministry of education of Humanities and Social Sciences (14YJC630152), China Postdoctoral Science Foundation(2014M562504XB), Science Technology Project of Chongqing Municipal Education Commission (KJ1400106) and Chongqing Postdoctoral Science Foundation (Xm2014070).

\section{References}

Bade, D., \& Mueller, J. (1999). New for the millennium: 4PL. Transportation\& Distribution, 40(2), 78- 80.

Ernst, F., \& Schmidt, K. M. (1999). A theory of fairness, competition and cooperation. Quarterly Journal of Economics, 114(3), 817-868. http://dx.doi.org/10.1162/003355399556151

Fulconis, F., Saglietto, L., \& Pache, G. (2006). Exploning new competencies in the logistics industry: The intermediation role of 4PL. Supply Chain Forum :An International Journal, 7(2), 68-77.

He, J., Wang, J., \& Jiang, X. L. (2013). The Price Risk Decision of Inventory Portfolio in Supply Chain Finance. 
Management Review, 25(11), 163-176.

He, J., Wang, J., \& Jiang, X. L. (2012). Mechanism Design of Avoiding Collusion in Inventory Financing under Incomplete Information. Soft Science, 26(8), 141-145.

Hertz, S., \& Alfredsson, M. (2003). Strategic development of third party logistics providers. Industrial Marketing Management, 32(2), 139-149. http://dx.doi.org/10.1016/S0019-8501(02)00228-6

Li, J., Xu, Y., \& Feng, G. Z. (2007). Game Analysis based on Inventory Financing. Productivity Research, 20, 49-50.

Li, W. (2011). Simple Analysis of the Logistics Supply Chain of Agricultural Products in Financial mode. Logistics Engineering and Management, 33(9), 44-45.

Li, Y. X., Feng, G. Z., \& Xu, Y. (2007). Research on Loan-to-value Ratio of Inventory Financing under Randomly-fluctuant Price. System Engineering-Theory \& Practice, 12, 43-48.

Luo, Q., Zhu, D. L., \& Chen, B. M. (2002). A Third party Logistics Service Innovation: Financing Warehouse and Its Operation Model. China Business and Market, 2, 11-14.

Rabin, M. (1993). Incorporating Fairness into Game Theory and Economics. The American Economics Review, 83(5), 1291-1302.

Stefansson, G. (2006). Collaborative logistics managment and the role of third-party service providers. International Journal of Physical Distribution and Logistics Management, 36(2), 76-92. http://dx.doi.org/10.1108/09600030610656413

Visser, E. J. (2007). Logistics innovation in global supply chains: An empirical test of dynamic transantion-cost theory. Geo Journal, 70(2), 213-226. http://dx.doi.org/10.1007/s10708-008-9133-0

Wang, Y., \& Xu, P. (2010). The Incentive Mechanism of Banks to 3PL Considering the Factor of Justice Preference Based on FTW of Principal-Agent Model. Journal of Industrial Engineering/Engineering Management, 24(1), 95-100.

Wei, Y., Sun, C. Y., \& Shuai, B. (2010). Design of Incentive Contract between Banks and 3PL based on Inventory Financing. Logistics Technology, 6, 73-77.

Xu, P., Wang, Y., \& Yang, J. (2010). Incentive and Supervisory Mechanism of Banks to 3PL based on Warehouse Receipt Pledge of Common Principal. Science Research Management, 31(3), 134-142.

Zhang, Y. F., \& Wang, Y. (2014). The Research on Inventory Pledge Financing Risk's Diagnosis Based on Catastrophe Progression Model. Journal of Industrial Technological Economics, 7, 66-74. 